\title{
BIODIVERSIDADE E HORTA COMUNITÁRIA: RELATO DE EXPERIÊNCIA ENVOLVENDO ALUNOS COM NECESSIDADES ESPECIAIS
}

\section{BIODIVERSITY AND COMMUNITY VEGETABLE GARDEN: EXPERIENCE REPORT INVOLVING STUDENTS WITH SPECIAL NEEDS}

DOI: $\underline{\text { http://dx.doi.org/10.5965/1984317815032019127 }}$

Rafaella Rodrigues Santos rafaella.rs020@gmail.com

Ana Clara Monte Teixeira anacmt@uol.com.br

Andreza Cristina Stuchi andrezacstuchi@gmail.com

Alexandre Junio Borges Araújo alexandrejuniob96@hotmail.com

Daniela Araújo Vilela danielaaraujovilela@gmail.com

Débora Queiroz Messias debora.messias@hotmail.com

Felipe Ferreira Naves felipefnaves@outlook.com.br

Julia Hass

juliahass@gmail.com

Lara Nascimento Zanato larazanatto@hotmail.com

Lara Parreira de Souza lara_parreira93@yahoo.com.br

Letícia Clemente OImos Hernandes le.clemente95@gmail.com

Lorraine Mendes Barrada lorraine mendes00@live.com

Mayara YukikoYamada mayarayukiko@hotmail.com

Rafael Galisa de Oliveira galliza@hotmail.com

Tamires do Carmo Dias do Carmo Dias dias.tamiresdc@gmail.com

Yasmin de Araújo Ribeiro yasminaraujo@hotmail.com

Neusa Elisa Carignato Sposito 
neusa.sposito@ufu.br

\section{Carla Patrícia Bejo Wolkers} carlawolkers@ufu.br

Universidade Federal de Uberlândia

\section{RESUMO}

Este trabalho trata-se de um relato de experiência sobre um projeto desenvolvido pelos integrantes do Programa de Educação Tutorial do curso de Ciências Biológicas (PET BIO PONTAL), juntamente com estudantes voluntários do mesmo curso da Universidade Federal de Uberlândia, Campus Pontal. O projeto envolveu os estudantes do $7^{\circ}$ ano do ensino fundamental de uma escola pública estadual de educação especial do município de Ituiutaba-MG e teve como objetivo abordar conteúdos sobre a biodiversidade de organismos viventes no ambiente de hortaliças, de maneira lúdica e inclusiva. Para isso, foram realizadas uma "dinâmica sensorial" para que os estudantes tivessem contato com as hortaliças, a implantação da horta na escola e a visita dos estudantes à universidade para análise das hortaliças e do solo, bem como dos organismos associados à eles. A realização deste projeto permitiu aos graduandos participantes uma experiência didática vivenciada fora da sala de aula convencional, junto a estudantes que apresentavam necessidades educacionais especiais (deficiências cognitivas), sendo enriquecedor para sua formação acadêmica e profissional. As dificuldades apresentadas durante a execução do projeto permitiram aos graduandos a reflexão acerca da educação inclusiva e o desenvolvimento de metodologias de trabalho que permitissem aperfeiçoar o ensino para este público. Observou-se que o projeto foi bem aceito pelo público-alvo, bem como pelos gestores da escola. Ainda, tornou mais evidente aos graduandos a exclusão sofrida pelos estudantes e a necessidade de repensar a educação, considerando as especificidades individuais de cada criança, especialmente aquelas que apresentam deficiências cognitivas.

Palavras-chave: Biodiversidade; Educação especial; Ensino de Ciências; PET.

\section{ABSTRACT}

The text is a research done in Salvador / BA, linked to the Postgraduate Program in Dance, with men who dance and their interfaces with the experience of sexuality and with the process of aging. The field research took place in three contexts: scene, teaching and independent artists. The first axes included ballet dancers from the Castro Alves Theater (BTCA) and dancers from the Dance School of the Cultural Foundation of the State of Bahia (FUNCEB). Semi-structured interviews were conducted with the artists and some classes and essays were observed and registered in a field diary. The preconception of the family, the privilege and autonomy of being a man, the resignification of the body and the dramaturgy of dance, as well as projects for the future were some of the most significant findings. The context of Salvador, which allows a rich experience of dance and its academic deepening, contributed significantly to the constitution of dance artists and their professional independence.

Keywords: Men. Sexuality. Aging. Gender. Teaching. 


\section{INTRODUÇÃO}

O desenvolvimento de políticas sociais que visem a inclusão de indivíduos com deficiência tanto no ambiente escolar quanto no ambiente de trabalho é essencial na tentativa de garantir a universalização dos direitos humanos constitucionais. A educação verdadeiramente inclusiva exige a elaboração de estratégias didático-pedagógicas diferenciadas, que primem por metodologias ativas de ensino-aprendizagem e que conduzam o aluno ao envolvimento direto com a atividade, permitindo-lhe construir o próprio conhecimento pela experiência vivenciada (SILVA, 2015).

Nas últimas décadas a questão da educação inclusiva e os desafios enfrentados para sua implementação têm sido alvo de ampla discussão. Em 1994 a Organização das Nações Unidas para a Educação, a Ciência e a Cultura (UNESCO) realizou a Conferência Mundial de Educação Especial, que resultou na Declaração de Salamanca, que definiu "Regras Padrões sobre Equalização de Oportunidades para Pessoas com Deficiências", as quais demandam que os Estados assegurem que a educação de pessoas com deficiências seja parte integrante do sistema educacional.

No Brasil, a Lei de Diretrizes e Bases da Educação (LDB, Lei $n^{\circ}$ 9.394), de 1996, também prevê a escola inclusiva em seu Artigo $4^{\circ}$, pontuando que é dever do estado o

[...] atendimento educacional especializado gratuito aos educandos com deficiência, transtornos globais do desenvolvimento e altas habilidades ou superdotação, transversal a todos os níveis, etapas e modalidades, preferencialmente na rede regular de ensino. (BRASIL, 1996, p. 8).

Além disso, o Plano Nacional de Educação (PNE, Lei n¹3.005 de 2014) prevê em seu artigo $8^{\circ} \S 1^{\circ}$ Inciso III a "garantia de atendimento educacional a estudantes com necessidades especiais de aprendizagem, a partir de um sistema de ensino inclusivo em todos os níveis" (BRASIL, 2014, p.4). Também, 
o artigo 27 da Lei 13.146 de 06 de julho de 2015 que instituiu a Inclusão da Pessoa com Deficiência (Estatuto da Pessoa com Deficiência) determina que

A educação constitui direito da pessoa com deficiência, assegurados sistema educacional inclusivo em todos os níveis e aprendizado ao longo de toda a vida, de forma a alcançar o máximo desenvolvimento possível de seus talentos e habilidades físicas, sensoriais, intelectuais e sociais, segundo suas características, interesses e necessidades de aprendizagem. (BRASIL, 2015, p.7).

Desta maneira, a legislação acima destaca a importância da existência de um sistema de educação inclusivo que possibilite ao aluno com deficiência, qualquer que seja ela, o máximo de aprendizagem, respeitando suas limitações. A existência de uma escola preparada para atendê-los, tal como a atendida neste projeto, não contempla estas determinações legais, pois por se tratar de uma escola de educação especial, fere os princípios primordiais da inclusão. De fato, no Brasil, as escolas de educação especial datam da década de 70 e constituem-se em um modelo educacional severamente questionado por perpetuarem a segregação dos discentes.

Portanto, mesmo constatando-se que o Brasil conta com uma legislação educacional que garante a inclusão de crianças e adolescentes portadores de necessidades especiais na rede regular de ensino, e com políticas públicas que são criadas com este intuito, existem dificuldades inerentes para sua efetivação, especialmente associadas à formação inadequada dos professores para atuarem junto aos alunos com necessidades educacionais especiais.

Outra dificuldade na implementação de práticas educativas verdadeiramente inclusivas é a gestão escolar que deve estar preparada para atuar junto a este público, ou seja,

A gestão [...] deve articular ações que fomentem não só a participação, mas também a formação, a reflexão de todos quanto às necessidades dos alunos com deficiência. Nesse sentido, um novo profissional precisa ser formado, fundamentado numa cultura que respeita a diversidade, promova a inclusão e garanta os direitos fundamentais dos 
homens, dentre eles o acesso à educação de qualidade. (SANTANNA, 2015, p.78).

Santana (2015) indica que é necessário formar novos profissionais que estejam preparados para atuar junto aos alunos com necessidades especiais. Esta formação implica na necessidade de se fomentar ações de formação continuada para professores, pois gerir uma escola sem que os professores estejam preparados para atuar junto aos alunos com necessidades especiais impede que a inclusão seja efetivada. Para tornar possível a construção de novas práticas pedagógicas que cumpram com as especificidades de cada aluno, o professor deve ter o compromisso com a inclusão e saber de sua importância, um compromisso que só pode ser concretizado através de capacitação continuada (SILVA, 2015).

Neste contexto, visando contribuir e realizar um trabalho direcionado ao ensino de Ciências para estudantes com necessidades educacionais especiais, o grupo do Programa Educação Tutorial (PET) do Curso de Ciências Biológicas da Universidade Federal de Uberlândia Campus Pontal "PET Bio Pontal" desenvolveu um projeto de educação inclusiva com estudantes de uma escola pública estadual de educação especial.

O objetivo do projeto foi apresentar os conceitos biológicos em um contexto lúdico e participativo, primando pela realização de atividades inclusivas que respeitassem a particularidade de cada indivíduo, permitindo o desenvolvimento de uma interação professor-aluno próxima, considerada por MRECH (1998) como essencial para o desenvolvimento intelecto-social de crianças que apresentam diagnóstico de deficiência intelectual.

O projeto teve a preocupação com a interação de todos os participantes do projeto, pois como indica Fonseca (2011)

[...] apesar de a aprendizagem ser um processo altamente individual, pois cada pessoa aprende de determinada forma, em determinado tempo, ela se dá de forma interativa, não só por meio de convivência, discussões, trocas interativas e intelectuais com pessoas semelhantes em sua forma de pensar, agir, interagir, como também em contato com pessoas 
totalmente diferentes no que se refere aos aspectos de vida pessoal, profissional e até intelectual. (FONSECA, 2011, p.87).

\subsection{0 ensino de ciências e os alunos com necessidades especiais}

Ensinar Ciências é sempre um desafio para os professores, pois é necessário partir do senso comum dos estudantes, construindo a explicação científica para os temas abordados a partir de suas concepções prévias. Neste contexto, é essencial que os docentes apresentem não só o domínio dos conteúdos científicos, como também de metodologias de ensino adequadas para garantir uma aprendizagem verdadeiramente significativa.

Ao partir do senso comum, o docente permite ao aluno estabelecer relações entre o conhecimento científico e seu dia-a-dia, proporcionando significado aos conteúdos aprendidos. De acordo com Capellini; Fonseca (2017)

O conhecimento só é assimilado pelo aluno quando este estabelecer relação entre o que já conhece e o que está tendo oportunidade de conhecer e, fazer a simbolização dando significado a determinado conhecimento, o ajudará a transformar-se e/ou transformar o ambiente em se está inserido. (CAPELLINI; FONSECA, 2017, p. 115).

No entanto, várias dificuldades podem surgir no ensino dos conhecimentos de Ciências, sendo a falta de preparo do professor uma das mais importantes. Estudo realizado por Augusto; Amaral (2015) junto a treze professoras polivalentes das séries iniciais do Ensino Fundamental constatou que as mesmas dificuldades em explicar os conteúdos de Ciências em virtude da "falta de conhecimento prévio dos conteúdos específicos de Ciências" ( $p$. 493) e, também, devido ao pouco tempo da grade horária destinado a este conteúdo. Além disso, estudo de Camargo; Blaszko; Ujiie (2015) sobre o Ensino de Ciências realizado com dezoito professoras das séries iniciais em uma escola pública municipal do estado do Paraná demonstrou que há pouca ênfase nesta disciplina nos anos iniciais, apontando a necessidade de 
investimento na formação continuada dos professores. No tocante aos estudantes com necessidades educacionais especiais, esta falta de investimento na formação continuada, associada à ausência de processos formativos direcionados a este público torna o ensino de Ciências ainda mais desafiador.

Neste contexto, inúmeros aspectos devem ser levados em consideração para mediar a aprendizagem de conceitos científicos, especialmente por estudantes com necessidades especiais. Para a pesquisadora Pletsch (2014)

[...] as possibilidades de apropriação dos conceitos científicos e da cultura pelas pessoas com deficiência intelectual especialmente aqueles que envolvem memória, criação, atenção, raciocínio lógico, interpretação, enfim as operações simbólicas como um todo - dependem das interações estabelecidas entre professor e aluno ou aluno e aluno durante as práticas pedagógicas, bem como dos estímulos aos quais são expostos em seu contexto social e cultural. Portanto, para que as práticas escolares possibilitem aos alunos com deficiência intelectual desenvolver novas formas de funcionamento mental, as mesmas devem priorizar o ensino dos conceitos, seus significados e sentidos. Esse aspecto reforça a importância da mediação e das experiências de aprendizagem a que os sujeitos são expostos no ambiente escolar. (PLETSCH, 2014, p.16).

Concordamos com Pletsch (2014) sobre a necessidade das interações entre os que ensinam e os que aprendem no momento do processo de ensino e aprendizagem dos alunos com necessidades especiais. Deste modo, o projeto desenvolvido pelo Grupo PET Bio Pontal, que será apresentado adiante, primou por oportunizar as interações entre aqueles que ensinavam e os alunos participantes e, também, entre eles próprios, proporcionando um ambiente de práticas de aprendizagens que estimularam a aprendizagem dos alunos sobre os conteúdos apresentados dentro do contexto escolar. 


\section{RELATO DA EXPERIÊNCIA: ESTUDO DA BIODIVERSIDADE ANIMAL ASSOCIADA À HORTA}

A dificuldade inerente ao desenvolvimento de atividades com Educação Inclusiva foi um dos agentes estimuladores para a escolha do projeto aqui relatado, que contou com a participação dos 12 bolsistas do grupo PET e sua tutora, 4 estudantes de graduação selecionados pelo grupo por meio de sorteio e uma classe de estudantes da disciplina de "Oficina de Ciências e Biologia" e sua professora responsável.

O projeto foi iniciado com o planejamento e organização da atividade. Considerando as necessidades especiais do público alvo o planejamento foi realizado com a devida atenção levando-se em conta que as atividades precisavam estar de acordo com o nível intelectual dos estudantes, empregando metodologias ativas e lúdicas de ensino-aprendizagem, incluindo dinâmicas que estimulava os sistemas sensoriais, técnicas de "brain storm", contato prático com solo e vegetais, entre outras.

A atividade foi desenvolvida em três etapas: (1) Apresentação do projeto e dos membros do grupo para os estudantes na escola; (2) Implantação de uma horta comunitária em conjunto com os estudantes na escola; (3) Visita dos estudantes aos laboratórios didáticos do curso de Ciências Biológicas da universidade para a análise das características biológicas da horta.

Antes do início dos trabalhos, representantes do grupo PET foram até a escola para apresentar a proposta da atividade à direção, que aprovou o desenvolvimento do projeto e esclareceu os mesmos sobre as características dos estudantes e sobre os tipos de deficiências cognitivas que seriam encontradas.

\subsection{Apresentação do projeto}

O primeiro encontro com os estudantes da escola teve como objetivo a apresentação do projeto e dos envolvidos em sua execução. 
Os trinta estudantes que participaram do projeto apresentavam, em sua totalidade, deficiências cognitivas e de aprendizagem, associadas ou não a síndromes genéticas diversas, não divulgadas pela escola, não havendo indivíduos com deficiências física, auditiva ou visual. Este primeiro momento foi importante para que o grupo tivesse um primeiro contato com os estudantes e conhecessem seus perfis e dificuldades, visando nortear o planejamento e execução das atividades posteriores para melhor atender aos estudantes e suas expectativas.

Nesta ocasião foram levados a escola exemplares de vegetais (verduras, legumes) que poderiam ser plantados na horta, para a realização de uma "dinâmica sensorial", a partir da qual os vegetais seriam apresentados aos estudantes. Durante a dinâmica, os estudantes foram encorajados a pegar as plantas na mão, cheirar, comer, sentir as diferentes texturas e observar as estruturas, possibilitando maior conhecimento dos elementos que, posteriormente, os próprios estudantes iriam trabalhar. Além disso, foi aplicada a técnica de brainstorming, conhecida como tempestade de ideias, considerada uma metodologia de exploração de ideias com o objetivo de encontrar soluções para problemas (DUGOSH et al., 2000). Neste momento, os alunos foram questionados sobre seus conhecimentos prévios sobre as plantas, permitindo que eles descrevessem suas experiências, utilizações rotineiras, incluindo alimentação, chás, remédios caseiros, entre outros, como mostrado na figura 1. Para melhor aproveitamento os estudantes foram divididos em três grupos de, aproximadamente, 10 integrantes que foram acompanhados por seus professores responsáveis durante todo o encontro. 


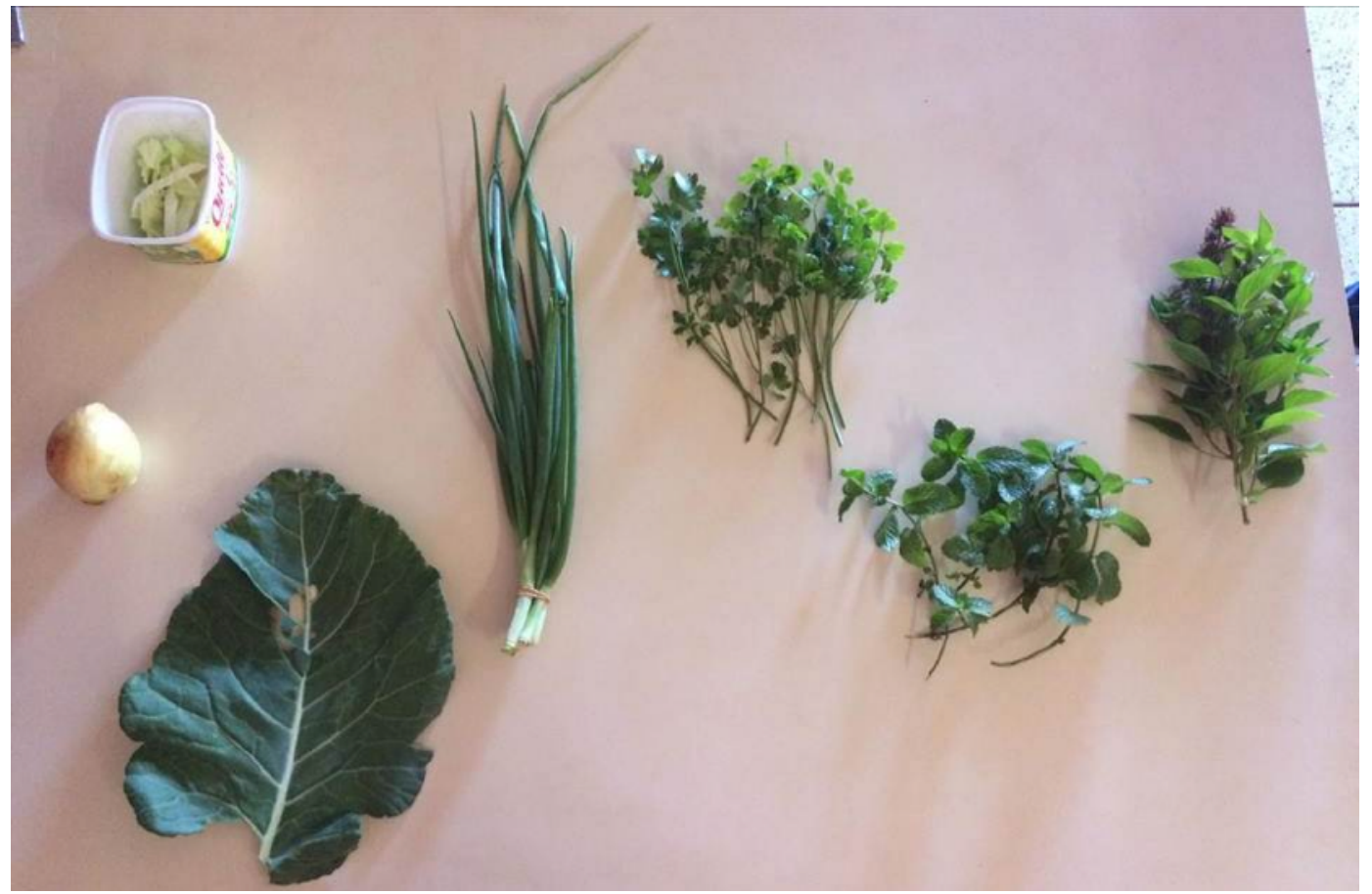

Figura 1: Vegetais que foram apresentados aos alunos na primeira visita à escola. Fonte: Os autores

\subsection{Implantação da horta}

No segundo encontro colocou-se em prática o conhecimento que os estudantes já haviam recebido em sala de aula com a professora de Ciências, sobre a preparação do solo para receber as mudas e sementes que foram anteriormente selecionadas e oferecidas pela própria escola, de acordo com a demanda na cozinha da mesma, considerando que a produção da horta seria destinada à merenda dos estudantes e para suas famílias.

O início dos trabalhos deu-se, portanto, com a preparação do terreno que receberia as mudas e sementes, onde foram realizadas a aeração, a adubação e a umidificação do solo para a plantação de mudas de alface, rúcula e manjericão e sementes de salsa e espinafre. Ressalta-se que todo o processo de implantação da horta foi realizado pelos estudantes da escola com auxílio dos bolsistas do PET e voluntários, sob supervisão da tutora do grupo PET e da professora de Ciências. As etapas de construção da horta na escola são apresentadas nas figuras 02 e 03. 


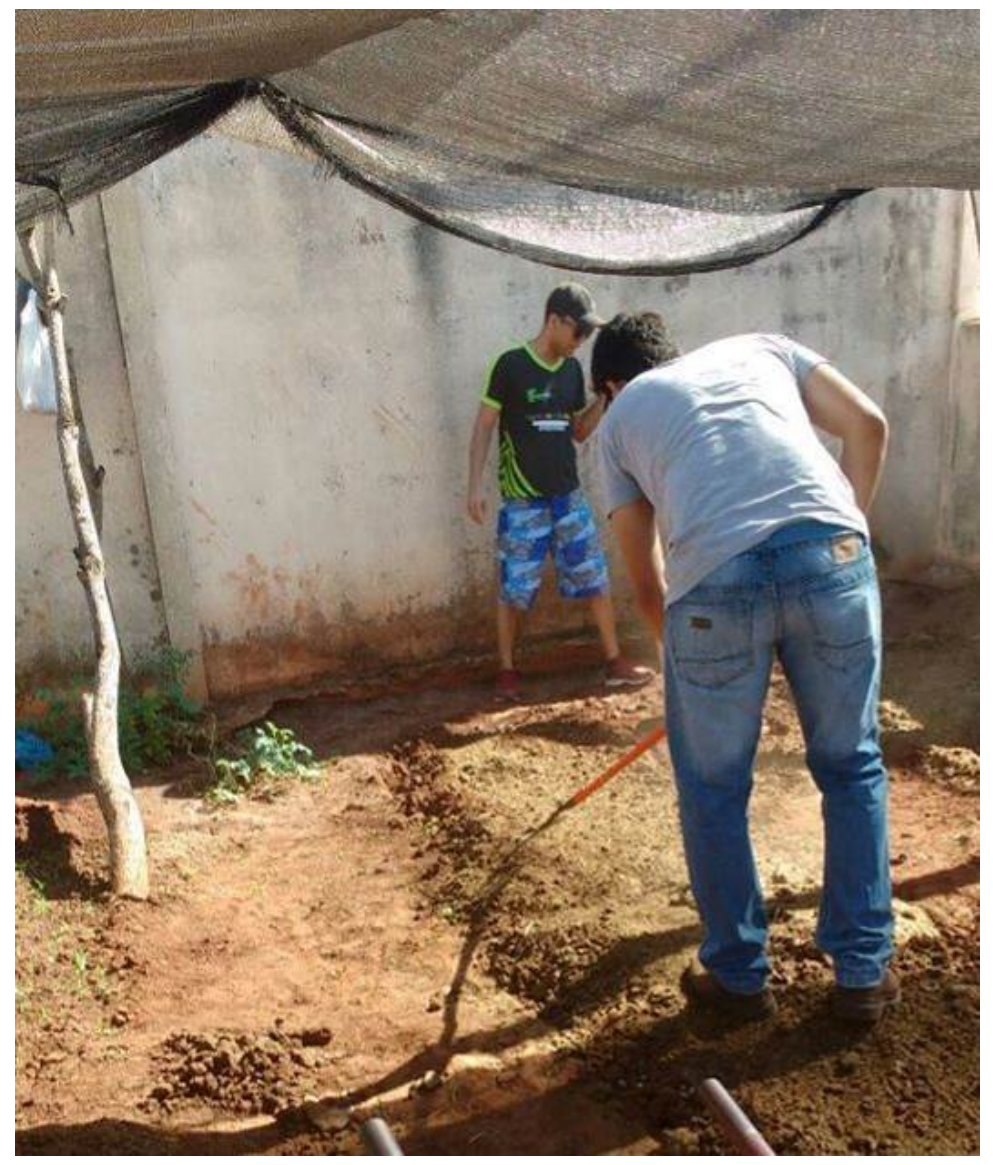

Figura 2: Preparo o solo para a plantação da horta Fonte :Os autores 


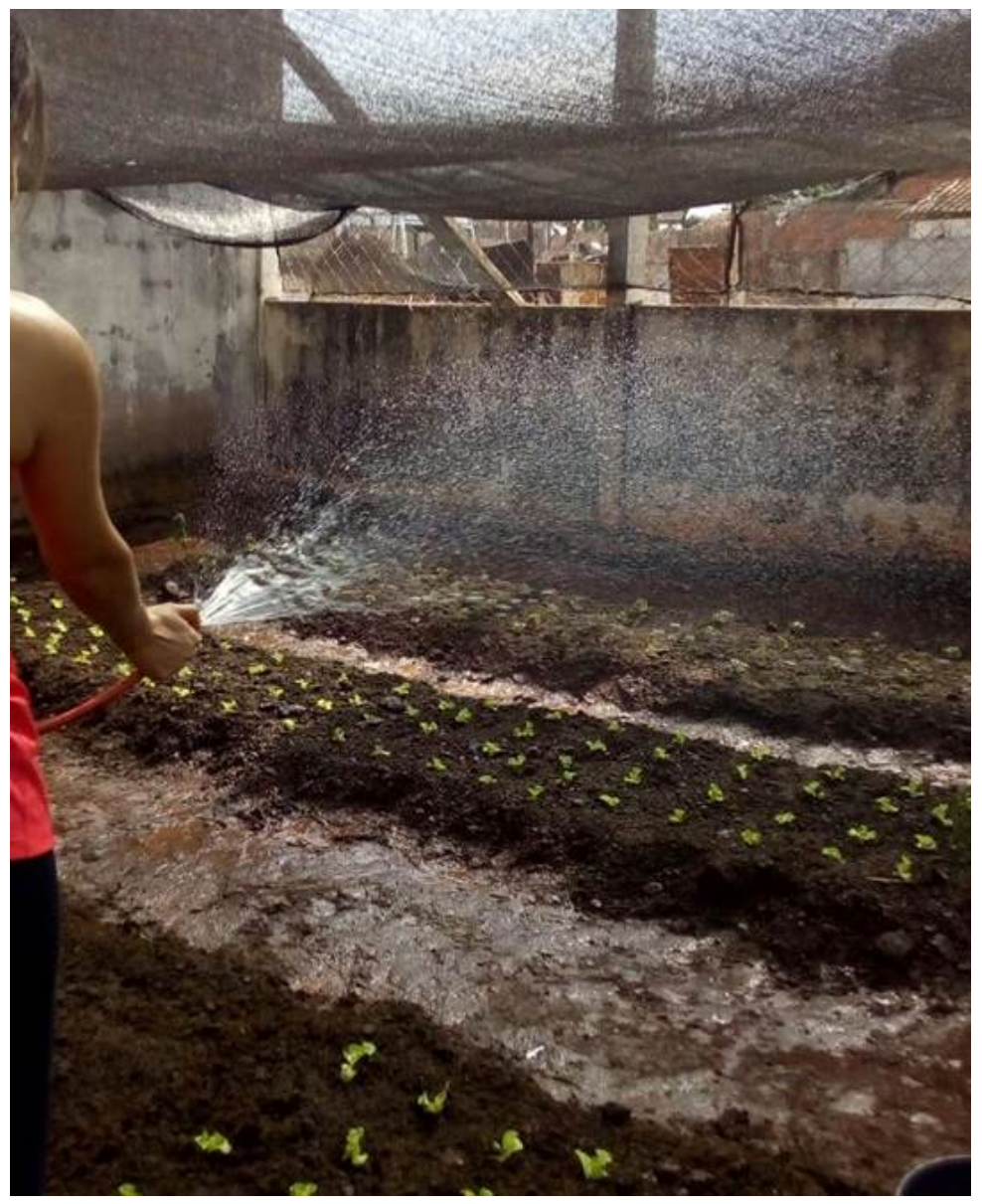

Figura 3: Umidificação dos canteiros da horta. Fonte :Os autores

Durante a implantação da horta os estudantes foram encorajados a colocar as mãos na terra para sentir as diferentes texturas do solo. Realizaram, ainda, com as próprias mãos a abertura das cavidades na terra, para a colocação das mudas. Este momento foi acompanhado de perto pelos monitores da atividade, que permaneceram ao lado dos estudantes, estimulando a participação ativa de cada um.

A interação entre os estudantes e o grupo foi próxima durante todo o processo de implantação da hora. Entretanto, apesar deste contato próximo, este momento foi considerado pelo grupo o mais crítico de todo o projeto, pois houve dificuldade em lidar com o comportamento dos estudantes, especialmente pela grande excitação provocada pela saída da sala de aula e pela presença de muitas pessoas no local. Em virtude disso, enquanto o 
planejamento inicial tinha como objetivo colaborar na construção dos conhecimentos dos estudantes sobre características físicas e biológicas de uma horta e a forma correta de implantação, na prática, houve grande dificuldade em chamar a atenção deles e fazê-los seguir as orientações, mesmo trabalhando com grupos pequenos, o que levou os promotores da oficina questionarem as metodologias aplicadas e as formas de trabalhar com o público em questão.

Após ampla reflexão, concluímos que o principal catalisador dos problemas enfrentados nesta etapa foi o foco do planejamento inicial ter sido direcionado para atividade e não aos estudantes envolvidos, propriamente ditos, o que nos levou a um questionamento primordial: como chamar a atenção de muitos estudantes, com deficiências cognitivas diversas e dificuldade de aprendizagem, agitação e interesses diversos? A partir deste momento de reflexão surgiu a ideia de ampliar o grupo para o desenvolvimento da terceira etapa do projeto, para que os estudantes pudessem ter atendimento individualizado, objetivando um melhor aproveitamento da atividade. Foi, então, proposta à professora da disciplina "Oficina de Ciências e Biologia" a realização de uma parceria para a participação dos discentes matriculados na disciplina como voluntários na terceira etapa do projeto.

A disciplina, ministrada pela professora da universidade, tem o objetivo de desenvolver metodologias de ensino para estudantes com diversos tipos de deficiência, buscando o combate à exclusão em sala de aula. A turma já havia realizado várias discussões, depoimentos de experiências vivenciadas e reflexões sobre as diversas formas de inclusão baseados em textos de referências sobre o assunto, tornando-os aptos ao desenvolvimento do projeto.

\subsection{Visita dos estudantes aos laboratórios didáticos do curso de ciências biológicas}

Para finalização do projeto o último encontro ocorreu na Universidade Federal de Uberlândia, Campus Pontal (UFU) onde os estudantes tiveram a oportunidade de conhecer as dependências da mesma e finalizar as atividades 
propostas. Ao chegar na universidade, os estudantes foram divididos em 2 grupos e cada um foi direcionado para um laboratório, que já estava preparado à sua espera.

Os laboratórios do curso de Ciências Biológicas estão localizados no terceiro andar do Bloco A desta instituição e contam com uma plataforma elevatória para uso de indivíduos com dificuldade de locomoção. Embora os alunos envolvidos no projeto não fossem deficientes físicos, alguns deles apresentavam algum nível de dificuldade de locomoção, sendo levados por meio da plataforma, acompanhados de um monitor. Os demais alunos acessaram o laboratório por meio das escadas. Todos apresentaram grande entusiasmo ao chegarem ao local e grande interesse em iniciar as atividades.

No laboratório, os estudantes, acompanhados individualmente por seus monitores, tiveram uma breve explicação e puderam visualizar as estruturas de uma planta, incluindo raiz, caule e folhas com o auxílio de estereomicroscópio (lupa) e foram apresentados para vários espécimes de animais viventes no ambiente de hortas, incluindo besouros, gafanhotos, minhocas e borboletas (Figura 4).

Os estudantes ficaram interessados ao observar os espécimes por meio do estereomicroscópio, por ser um equipamento com o qual nunca haviam tido contato. Alguns deles apresentaram dificuldade em observar as estruturas através do equipamento, mas o atendimento individual permitiu que cada um tivesse o tempo necessário e o acompanhamento adequado para se adaptar ao equipamento e conseguir observar as estruturas apresentadas.

Durante as explicações foram abordadas as funções de cada animal para as plantas, se esses são bons ou ruins ao desenvolvimento das mesmas e, ao final, foi proposto um exercício para que estudantes colassem figuras dos animais separando-os em dois quadros, bons e ruins, de acordo com as explicações já realizadas. 


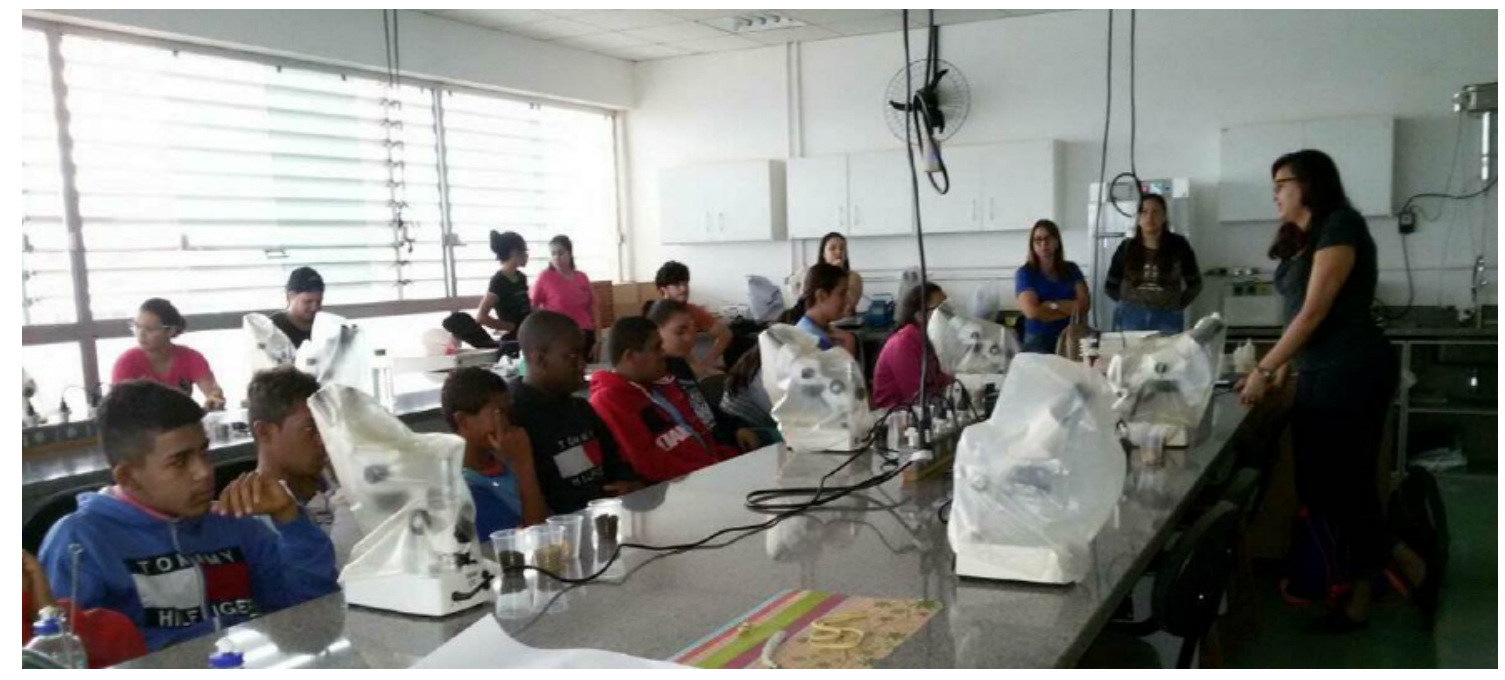

Figura 4: Apresentação do Laboratório aos visitantes Fonte :Os autores (2017)

Para trabalhar a importância da higienização dos alimentos colhidos da horta e das mãos antes do consumo destes alimentos, foi abordada a presença de organismos parasitas no solo, com especial atenção aos helmintos. Foram apresentados aos estudantes espécimes de Taenia solium e Ascaris lumbricoides, acompanhadas de explicações sobre seus ciclos de vida e as doenças causadas por eles. Foram utilizados desenhos esquemáticos para auxiliar na compreensão dos alunos a respeito do ciclo de vida destes helmintos e seus potenciais riscos para a saúde. Os estudantes ficaram entusiasmados ao observar os helmintos apresentados pelos monitores e a maior parte deles mostrou-se interessada e curiosa com relação aos helmintos, enquanto alguns demonstraram repulsa, o que contribuiu com o reforço dado pelo monitor sobre a importância de sempre se lavar as mãos e os alimentos antes de comer.

Também, foi realizada a exposição dos possíveis tipos de solos que podem estar presentes na horta: terra vermelha, areia, argila e esterco, e foi explicado aos estudantes a diferença granular e a capacidade de absorção de água de cada um. Durante a apresentação dos solos os monitores encorajaram os estudantes a colocar as mãos nos diferentes tipos de solo, sentirem as diferentes texturas antes e depois da colocação da água. Foi possível observar 
que os estudantes ficavam bastante intrigados com as diferentes texturas de solo apresentadas, especialmente quando o solo era molhado. Alguns estudantes não quiseram colocar a mãos no solo molhado, pois não queriam sujar as mãos, sendo este desejo respeitado.

Após a realização das atividades acima descritas por todos os alunos, encerrou-se a última etapa do projeto, que teve cerca de 60 pessoas envolvidas, incluindo membros do grupo PET, voluntários e estudantes, e uma duração média de 2 horas. Ressalta-se que cada estudante levou um tempo diferente no desenvolvimento da atividade, pois foi respeitado o tempo de aprendizagem de cada um e o tempo necessário para que cada etapa fosse concluída de maneira satisfatória.

O ponto principal desta terceira etapa foi o atendimento individualizado aos estudantes. O monitor designado para cada estudante acompanhou-o do início ao final da atividade, respeitando suas dificuldades e seu tempo de aprendizagem. Este atendimento individual permitiu a construção de uma relação de confiança entre monitor e estudante, garantindo um aprendizado significativo e personalizado, considerando as dificuldades individuais, conhecimentos prévios e curiosidades de cada um.

\section{DISCUSSÃO DA ATIVIDADE}

\subsection{Elaboração do projeto}

O programa PET tem como pressuposto o desenvolvimento de projetos apoiados pela tríade Pesquisa-Ensino-Extensão, tendo como prioridade o desenvolvimento de ações que permitam o compartilhamento dos conhecimentos produzidos na Universidade com a comunidade externa. Neste projeto, o público alvo foi os alunos de uma escola pública de atendimento à estudantes com necessidades especiais, visando a implementação de práticas de inclusão por meio do conhecimento. 
Neste projeto, foi proposto um conjunto de atividades de ensino de ciências inédito tanto para eles e para os alunos em questão, permitindo uma colaboração mútua "[...] entre professor e aluno ou aluno e aluno durante as práticas pedagógicas, bem como dos estímulos aos quais são expostos em seu contexto social e cultural." (PLETSCH, 2014, p.16)

Ao trabalhar no contexto de uma escola de educação especial, os graduandos do grupo PET e demais voluntários presenciaram as dificuldades de se desenvolver atividades didáticas com estudantes de diferentes faixas etárias e diversos tipos de deficiências cognitivas, colocados em uma mesma sala de aula e com um único professor. A partir da reflexão oportunizada pelas discussões e planejamento das atividades foi possível observar que o professor que atuar em classes com alunos na citada situação deve estar compromissado com este contexto e, de acordo com Silva (2015), é essencial que seja oportunizada a educação continuada para que estes profissionais estejam munidos dos conhecimentos necessários para atender a este público.

\subsection{Apresentação do projeto}

O grupo de alunos da universidade comunicou à direção da escola a intenção de apresentar o projeto e, assim, obter a necessária autorização para o desenvolvimento do mesmo. Foi feito, ainda, um contato inicial com os estudantes desta escola para conhecê-los e nortear o desenvolvimento do projeto de acordo com os seus respectivos perfis e expectativas. Com essa finalidade realizaram a dinâmica interativa sensorial com alguns vegetais em que os participantes por meio dos cinco sentidos puderam aprender sobre os mesmos. Também, utilizaram a técnica do brainstorming, em que os participantes puderam expor palavras, pensamentos e sensações que associavam ao que era apresentado pelo grupo. Esta técnica permitiu conhecer as concepções prévias apresentadas por cada aluno acerca da temática a ser trabalhada no decorrer do projeto e permitiu nortear o planejamento das atividades subsequentes. 
Entretanto, apesar da dinâmica sensorial ter permitido aos estudantes um contato mais próximo com os vegetais, bem como a expressão de seus sentimentos e memórias por meio do braimstorming, considera-se que este contato inicial não forneceu todos os subsídios necessários para 0 planejamento adequado do projeto, devido às dificuldades encontradas na etapa posterior. Para o desenvolvimento de atividades atendendo a especificidade deste público é necessário uma ampla gama de conhecimentos teóricos que o grupo não dispunha para atuar junto a estes discentes. No entanto, ressalta-se a importância deste grupo de graduandos em propor-se tal desafio e buscar a fundamentação e as atividades pertinentes na especificidade dos alunos da escola citada. Além disso, o contato contínuo com os alunos permitiu que o grupo refletisse sobre suas ações, buscando corrigir os problemas encontrados com o objetivo de prover um processo de ensinoaprendizagem adequado e eficiente. Trata-se de um compromisso social com esta parcela de alunos e que seria construído no decorrer da atividade proposta.

Como indicado por Capellini e Fonseca (2017) tratou-se de práticas educativas que ajudaram tanto os discentes da Educação Básica como os universitários "a encontrarem conexões entre o que já conhecem e o que é novo" (p.117).

\subsection{A implantação da horta}

Esta fase do projeto ampliou o convívio com o grupo de graduandos e os alunos e professoras da escola pública. Constatou-se que nesta escola os alunos, em geral, desenvolvem suas atividades dentro de sala de aula, pois os mesmos ficaram eufóricos quando puderam ir para o local onde seria construída a horta, dificultando a implantação do projeto idealizado pelos universitários. Ainda, aponta-se que a euforia apresentada por estes alunos parece ser a mesma que ocorre entre a maioria alunos das escolas públicas, ou seja, trata-se de uma manifestação indicativa de que o confinamento dos alunos em salas de aula não é sentido com satisfação. 
A dificuldade o grupo PET encontrou para organizar os grupos, mesmo com a ajuda das professoras da escola, nos levou ao questionamento da metodologia utilizada e à reflexão de que seria necessário direcionar o foco para os alunos envolvidos e não para a atividade planejada. Neste momento o grupo PET pôde perceber que ensinar não é apenas saber e transmitir um conteúdo, mas, sim que ensinar requer uma metodologia adequada, e qual é ela?

A resposta é complexa e não será discutida aqui, apenas aponta-se que para aquele que ensina este é um momento indicativo e crucial da necessidade de construir e apropriar-se de uma metodologia específica para o processo de ensino e aprendizagem dos diferentes conteúdos. Para Pleisch (2014), ensinar os conhecimentos científicos às pessoas com deficiência intelectual requer o estabelecimento de interações "entre professor e aluno ou aluno e aluno durante as práticas pedagógicas, bem como dos estímulos aos quais são expostos em seu contexto social e cultural". (p.16). A partir desta reflexão, foi percebida a necessidade de implementação de uma metodologia de ensino personalizada para cada estudante, considerando a especificidade das necessidades de cada um dos alunos, primando por uma relação próxima entre quem ensina e quem aprende.

\subsection{Visita dos estudantes aos Laboratórios Didáticos do Curso de Ciências Biológicas}

Esta etapa do projeto permitiu que cada graduando acompanhasse um estudante criando, entre eles, uma relação de proximidade. A partir deste contato individual foi possível determinar quais eram as dificuldades cognitivas de cada aluno, bem como direcionar o desenvolvimento das atividades para atender à estas dificuldades. A educação é um processo interativo, que requer o diálogo entre professor e aluno. Para Freire (1996, p.77) "toda prática educativa demanda a existência de sujeitos, um, que ensinando, aprende, outro, que aprendendo ensina". Quando o professor estabelece este vínculo, a aprendizagem mútua é oportunizada, permitindo que o aluno se expresse e 
deixe de ser um sujeito passivo no processo educacional, passando a participar ativamente nesta interação.

A experiência didática proporcionada aos graduandos no contato direto com os alunos, bem como a reflexão sobre a prática docente no decorrer do projeto contribuiu para a construção da identidade docente destes professores em processo de formação, corroborando a célebre frase de Paulo Freire: "Ninguém nasce educador ou marcado para ser educador. A gente se faz educador, a gente se forma, como educador, permanentemente, na prática e na reflexão da prática". (FREIRE, 1991, p. 58). É na prática, alicerçada na fundamentação teórica, que o professor se constitui, sendo assim, são as experiências educacionais dentro e fora dos ambientes formativos que constituem o educador.

Embora seja claro o despreparo, tanto de professores já atuantes, quanto daqueles em processo de formação no que diz respeito à implementação da educação inclusiva, a escola verdadeiramente inclusiva não nasce simplesmente das legislações e políticas públicas vigentes, "a escola inclusiva constrói-se" (SILVA, 2011, p.1). Para Silva (2011), a escola inclusiva depende de suporte legislativo, entretanto ela só pode ser consolidada com a prática dos atores que a implementam. Não é apenas sobre saber como se faz, mas sobre querer fazer e acreditar que é possível construir uma escola verdadeiramente inclusiva.

\subsection{A escola inclusiva ou exclusiva?}

Esta experiência evidenciou de maneira bastante clara a exclusão social que indivíduos com deficiências cognitivas enfrentam em seu dia-a-dia, a segregação gerada por este ambiente escolar e o quanto esta realidade se afasta da desejada educação inclusiva. Esta constatação por parte dos promotores das atividades deste projeto demonstra que os mesmos estão cientes ou ficaram cientes da existência do preconceito e segregação que sofre esta parcela de estudantes, que frequentam uma escola específica para ele, 
afastados dos demais estudantes, indo contra as determinações legais como as que constam no início deste artigo.

\section{CONSIDERAÇÕES FINAIS}

O desenvolvimento deste projeto permitiu não só levar conhecimento na área das Ciências aos estudantes da Escola de Educação Especial de maneira lúdica e significativa, mas também possibilitou uma experiência prática aos graduandos do curso de Ciências Biológicas, que tiveram a oportunidade de ter contato direto com uma realidade diferente de uma sala de aula regular, levando-os a uma reflexão bastante complexa das diferentes metodologias a serem aplicadas no ensino de Ciências e Biologia. Foi observada a necessidade de um atendimento educacional personalizado, para cada estudante, levando em consideração suas deficiências e dificuldades de aprendizagem. Observou-se ainda o potencial do desenvolvimento de atividades que estimulam os sistemas sensoriais destes indivíduos, gerando experiências sensoriais mais ricas e significativas para cada um deles. Além disso, metodologias que valorizam as memórias e concepções prévias dos estudantes mostraram-se norteadores para a construção do conhecimento científico a partir do senso comum e do imaginário de cada aluno. A experiência aqui relatada reforça a importância da realização de atividades de caráter extensivo às salas de aula não convencionais, e a necessidade de enfrentamento de realidades diferentes, e muitas vezes, distantes do ambiente acadêmico universitário.

As dificuldades no atendimento de estudantes com deficiências se inicia na formação profissional do professor, dentro dos cursos de Licenciatura, que, em sua maioria, não apresentam uma formação adequada no que concerne os fundamentos da educação inclusiva e os métodos e materiais que podem ser utilizados para viabilizar a aprendizagem destes estudantes e, especialmente, a inclusão destes na rede regular de ensino, conforme previsto na LDB. Ao finalizarem sua formação e entrarem no mercado de trabalho os jovens 
professores se deparam com as dificuldades inerentes da profissão e não estão preparados para lidar com a realidade escolar. Dessa maneira, é essencial que o curso de graduação em licenciatura seja palco de discussões relacionadas a esta temática, permitindo que os professores tenham uma formação mais profunda e voltada à educação inclusiva.

Embora as mudanças requeridas no sistema educacional para a implementação da educação inclusiva sejam profundas, o desenvolvimento de projetos de extensão como este aqui apresentado permitem confrontar os graduandos, docentes em processo de formação, com a realidade educacional da região onde estão inseridos, levando-os a uma reflexão profunda sobre as lacunas de sua própria formação como futuro professor e impelindo-os na busca do conhecimento necessário para mudar esta realidade.

\section{AGRADECIMENTOS}

Agradecemos à Universidade Federal de Uberlândia representada pelo Programa de Educação Tutorial do curso de Ciências Biológicas - PET BIO Pontal, à Profa. Dra. Karine Rezende de Oliveira e aos demais discentes voluntários do projeto.

\section{REFERÊNCIAS}

AUGUSTO, Thaís Gimenez da Silva; AMARAL, Ivan Amorosino. A formação de professoras para o ensino de ciências nas séries iniciais: análise dos efeitos de uma proposta inovadora. Ciência \& Educação (Bauru), v. 21, n. 2, p. 493-509, 2015.

BRASIL. Senado Federal. Constituição da República Federativa do Brasil. Brasília, DF: Centro Gráfico, 1988.

- Congresso Nacional. Lei de Diretrizes e Bases da Educação Nacional - LDB. Lei n. 9.394, 20 de Dezembro de 1996. Brasília, DF: Congresso Nacional, 1996. 
. Ministério da Educação - MEC. Manual de Orientações Básicas do Programa de Educação Tutorial. SESu MEC - Brasília, dezembro de 2006.

Congresso Nacional. Lei n. 13.005, de 25 de Junho de 2014. Plano Nacional de Educação (2014-2024). Brasília, DF. 2014.

Presidência da República. Lei Brasileira de Inclusão de Pessoas com Deficiência (Estatuto da Pessoa com Deficiência). Lei n.13.146, de 06 de julho de 2015. Brasília, julho, 2015.

CAMARGO, N. S. J.; BLASZKO, C. E.; UJIIE, N. T. O ensino de ciências e o papel do professor: concepções de professores dos anos iniciais do ensino fundamental. Anais. XII Congresso Nacional de Educação - EDUCERE. p. 2212 a 2227, 2015.

CAPELLINI, Vera Lúcia Messias Fialho; DE ABREU FONSECA, Kátia. A escola inclusiva: seus pressupostos e movimentos. DOXA: Revista Brasileira de Psicologia e Educação, v. 19, n. 1, p. 107-127, 2017.

DUGOSH, Karen Leggett et al. Cognitive stimulation in brainstorming. Journal of personality and social psychology, v. 79, n. 5, p. 722, 2000.

FONSECA, K. A. Análise de adequações curriculares no ensino fundamental: subsídios para programas de pesquisa colaborativa na formação de professores. 2011. 126f. Dissertação (Mestrado em Psicologia do Desenvolvimento e Aprendizagem) - Universidade Estadual Paulista, Faculdade de Ciências, Bauru, 2011.

FREIRE, Paulo. A educação na cidade. São Paulo: Cortez, 1991.

Pedagogia da autonomia: saberes necessários à prática educativa. 20 ed. São Paulo: Paz e Terra, 1996.

MRECH, Leny Magalhães. O que é educação inclusiva. Revista Integração, v. 10 , n. 20 , p. $37-40,1998$.

PLETSH, Márcia Denise. Educação especial e inclusão escolar: políticas, práticas curriculares e processos de ensino e aprendizagem. Poíesis Pedagógica, v. 12, n. 1, p. 7-26, 2014.

SANTANNA, Adriene. A gestão escolar no contexto da educação inclusiva: a educação especial em questão. Revista de Educação do Vale do ArinosRELVA, v. 2, n. 1, 2015.

SILVA, Cirlene. Os desafios da educação inclusiva e a escola hoje. Anuário de Produções Acadêmico-científicas dos Discentes da Faculdade Araguaia, 
Araguaia, v. 3, n. 1, p.133-146, mar. 2015.

SILVA, Maria Odete Emygdio. Educação Inclusiva - um novo paradigma de Escola. Revista Lusófona de Educação, v. 19, p. 119-134, 2011. 